\title{
ПЕРСОНАЛИЗИРОВАННЫЙ ПОДХОД К ОПРЕДЕЛЕНИЮ ПРЕДИКТОРОВ КАРДИО- МЕТАБОЛИЧЕСКИХ НАРУШЕНИЙ У ПАЦИЕНТОВ С РАССЕЯННЫМ СКЛЕРОЗОМ, ПОЛУЧАЮЩИХ ГЛЮКОКОРТИКОИДНУЮ ТЕРАПИЮ
}

\author{
Бровкина С.С., Джериева И.С. \\ ФГБОУ ВО РостГМУ Минздрава России, Ростов-на-Дону
}

ЦЕЛЬ: оценить влияние глюкокортикоидов (ГК) на формирование кардио-метаболических рисков, а также состояние мышечной силы и массы у пациентов с рассеянным склерозом (РС).

МАТЕРИАЛЫ И МЕТОДЫ: Исследование проведено на базе клиники ФГБОУ ВО РостГМУ Минздрава России. Обследованы 42 пациента (57\% женщины) с подтвержденным РС в возрасте 20-45 лет, сформированы 2 группы: 22 пациента на ГК терапии (метилпреднизолон, преднизолон, дексаметазон), 20 человек - нет. Средний возраст 37,8 (20-45) лет, продолжительность болезни 5,9 1,2 года, оценка неврологом по расширенной шкале статуса инвалидизации Куртцке (EDSS) 3,3 1,2.

Мышечная сила оценена при помощи теста с подъемом со стула, силы захвата рук динамометром ДМЭР 120. Состав тела определен путем биоимпедансного анализа. Лабораторно оценивали глюкозу венозной плазмы натощак, $\mathrm{HbA}_{1 c^{\prime}}$ общий холестерин, липопротеиды низкой плотности (ЛПНП), липопротеиды высокой плотности, триглицериды. Оценены артериальное давление (АД), индекс массы тела (ИМТ), объем талии (ОТ), бедер, плеча, запястья. Проведен анализ дневников физической активности.

Статистический анализ проводился с помощью программы «Statistica 10.0». Нормальность распределения определяли тестом Шапиро-Уилка, p>0,05. Ненормально распределенные значения представлены в виде медианы и диапазона, нормально распределенные значения - как среднее \pm стандартное отклонение. Для анализа количественных и порядковых переменных использовали U-критерий Манна-Уитни, критерий $\chi^{2}, p<0,05$.

РЕЗУЛЬТАТЫ: группы были сопоставимы по полу, возрасту, продолжительности заболевания. Пациенты в 1 группе получали 25 (20-60) мг/сут в пересчете на преднизолон по 10 (5-30) дней. В 1 группе

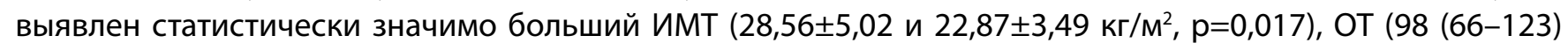

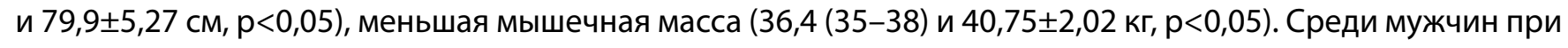
помощи коэффициента корреляции Спирмена отмечена значимая отрицательная связь дозы ГК и мышечной силы доминантной руки $(r=-0,88, p<0,0001)$.

В 1 группе выделены 9 человек с ОТ<80 и 94 см для женщин и мужчин. В данной подгруппе при срав-

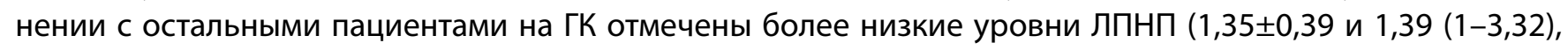

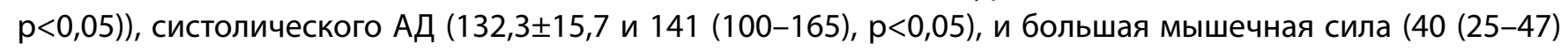

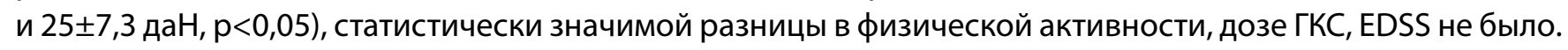

ВЫВоды: подтверждено негативное влияние ГК на кардио-метаболические параметры у пациентов с РС, а также мышечную силу у мужчин. В связи с чем, на фоне ГК терапии рационально выполнение динамометрии особенно у пациентов мужского пола, оценка ОТ, липидного обмена для своевременного выявления нарушений и их коррекции с целью предотвращения развития сердечно-сосудистых заболеваний, повышения качества жизни. Выделена группа пациентов с более здоровым метаболическим профилем на фоне ГК. Такая относительная резистентность к ГК в том числе может быть обусловлена генетически. Данная находка перспективна для исследования факторов защиты от негативного влияния ГК.

КЛЮЧЕВЫЕ СЛОВА: глюкокортикоиды; кардио-метаболические риски; рассеянный склероз. 